\title{
The Role of Artificial Intelligence in Teacher Professional Development
}

\author{
Hashem Mahmoud Muslim al-Zyoud \\ Ministry of Education, Teacher Training Institute, United Arab Emirates \\ Received July 27, 2020; Revised September 11, 2020; Accepted September 29, 2020
}

\section{Cite This Paper in the following Citation Styles}

(a): [1] Hashem Mahmoud Muslim al-Zyoud , "The Role of Artificial Intelligence in Teacher Professional Development," Universal Journal of Educational Research, Vol. 8, No. 11B, pp. 6263 - 6272, 2020. DOI: 10.13189/ujer.2020.082265.

(b): Hashem Mahmoud Muslim al-Zyoud (2020). The Role of Artificial Intelligence in Teacher Professional Development. Universal Journal of Educational Research, 8(11B), 6263 - 6272. DOI: 10.13189/ujer.2020.082265.

Copyright $\mathrm{C} 2020$ by authors, all rights reserved. Authors agree that this article remains permanently open access under the terms of the Creative Commons Attribution License 4.0 International License

\begin{abstract}
This paper aims to present the idea, development, and field of artificial intelligence (AI), considering its impact on teachers' professional development. In addition to the technical applications that support AI in the educational sector, and the problems facing its uses, the importance of artificial intelligence in the education field has been addressed and previous study cases that competed AI with commentary have been identified. This study uses an analytical approach based on a theoretical survey of previous literature to answer the study questions. The results refer to a set of intelligent applications as well as areas of artificial intelligence that can serve the professional development of teachers. Furthermore, we recommend to: Design educational software based on artificial intelligence to raise the qualifications of teachers, Build training pathways based on artificial intelligence for all those working in the field of education, Provide accurate databases in all areas' education including human resources, Provide educational training environments that add to improving the part of artificial intelligence applications in the professional development of teachers, and Link databases within a global network that helps challenge teachers' career paths.
\end{abstract}

Keywords Artificial Intelligence, AI, Professional Development for Teachers, E-learning, Digital Age, Education

\section{Introduction}

Intelligence has been a characteristic of human beings since ancient times, where intelligence was considered the greatest proof of the Creator's selection, the highest, of human beings in relation to all other creatures. It is natural that certain characteristics support this selection.

The human mind, the most important, is the first of these signs. Over time, it has become evident that the source of man's strength and distinction from other creatures is his intelligence. Scientists have studied the characteristic of intelligence in man and how it can be transferred to the machine. They take advantage of this to perform tasks at the level of human intelligence and the performance of the machine and its unforgettable power in every aspect of intelligence. His work is limited to traditional tasks far from creativity and innovation.

But with the dawn of the third millennium, which has seen fundamental changes with positive results in the pattern of the relationship between human intelligence, its benefits and the machine based on modern technology; and after the spread of computers and their use. The administrators' emphasis on neural networks, and the orientation towards systems based on knowledge representation continued to work during the 70 's. With the beginning of the 80 's, after the announcement of the Japanese project that sought the fifth generation of computers, there was a big boom in the wings of artificial intelligence.

In 1977, Professor (Faygenbaumn), the expert of artificial intelligence, presented a research paper to the Stanford University in America at the International Artificial Intelligence Conference. Therefore, later research focused on extracting knowledge from experts rather than focusing on complex inferential processes, which suffer from a lack of practical applications [1].

Questions began to be asked: How does this small brain; 
biological or electronic; understand, perceive, predict, and interact with a larger and more complex world than the brain itself? How can you take a road that is concerned with making small hallmarks with all its complex characteristics? And when searching for the mayors' answers to the questions, we find that the artificial intelligence is based on solid and firm foundations. And if we want to approximate this image that may appear to the eyes of some far-fetched but difficult to imagine, it is enough to look at the woman to find us alive thanks to the intelligent system. [2].

Therefore, the trend towards artificial intelligence appeared to simulate human intelligence and study its mental capabilities. While trying to comprehend the cycles of the human intellect, in a manner that leaves from the study of philosophy, psychology, and anatomy. As it deals with the human brain as a branched phenomenon that unifies its data in certain unique characteristics. Thus, it becomes clear that artificial intelligence seeks to build intelligence to the degree which means understanding this insight. Among the most significant reasons for studying artificial intelligence is what resulted from the utilization of computers with regard to identify different shapes, symbols and models. Where artificial intelligence systems appeared, which are characterized by the transfer of part of the methods of human intelligence to the wild systems of computers, which thus helps to assemble the exchange of experience that includes those of the human mind [3].

It very well may be said that AI programs offer numerous advantages in various zones of contemporary life that have acquired digital character based on advanced technology. Albeit nobody can anticipate the subtleties of things to come, obviously computers with human intelligence will have an enormous and significant effect on the eventual fate of human daily life. In the manufacture of new patterns and stereotypes about the scientific and civilizational development in the human future. where artificial intelligence is an overly attractive field of interest for scientists in the modern era only.

Scientists in general and education in particular are interested in artificial intelligence, this field that is witnessing innovations and continuous developments as it will have a positive role in the future. It is centered around the structure of a machine capable of participating human in behaviors described as smart, and humanity has become we use many systems that depend on this science in the north of the economy, medicine, engineering, training of armies, games, education, etc. Through highly sophisticated technology, things that humans in the recent past have been paying exorbitant amounts can be identified, prohibiting long times that can last months or years, and travelling thousands of kilometers on land and sea miles to reach them. But through the use of advanced technology, all of this has been easily accessed with ease and accuracy [4].
E-learning and online learning have great benefit because of their clear impact in raising the level of cognitive achievement. Given the exercises that are described by wise learning frameworks, for example, the capacity to adjust time to the necessities of the learners. Provide group learning opportunities with a group of students working to solve issues in specific environments. The important things in building smart learning systems appear by reducing the time and cost of designing and developing this grievance, among the strategies put forward and the use of authoring tools. Building systems in a methodic manner [5].

With the gradual integration of information technology and education and teaching, the innovative application of education informatization has brought new opportunities for teacher evaluation and professional development. "the article integrates "recognition in action" and "reflection in practice" with artificial intelligence technology, and establishes a new framework for teacher development evaluation based on teaching reflection, and integrates process diagnosis end reflective practice supported by intelligent technology into the teaching evaluation link. It solves the long- standing practical problems of "conflict between evaluation and feedback" and "disconnection between feedback and development" in the past teaching evaluation, so as to provide theory and application reference to the execution of educator improvement assessment with regards to intelligence instruction [24].

Referring to previous studies related to the subject of our research, there are not many Arab and foreign investigations that tended to the part of $\mathrm{AI}$ in the professional development of teachers, where most of studies focused on addressing the topic of artificial intelligence and highlighting its role in educational applications, contributing to the provision of high-quality curricula, educational environments that develop different thinking patterns, especially higher thinking skills in the student.

In a study conducted by Shelby in 1991 which demonstrates the experience of using artificial intelligence strategies in the planning and programming of courses.

The results of the open education study at Alexandria University in Egypt showed a consensus of opinion between the referees and the researcher on value of the programs as an experiment in popularizing e-learning at the general level and at the level of higher education.

The application of AI algorithms and systems in education are gaining increased interest year by year. (Figure 1) shows the rising number of papers published in the topics "AI" and "Education" from Web of Science and Google scholar since 2010. Note that the papers published in 2015-2019 accounted for a large proportion, i.e., $70 \%$ of all the papers.[8] 


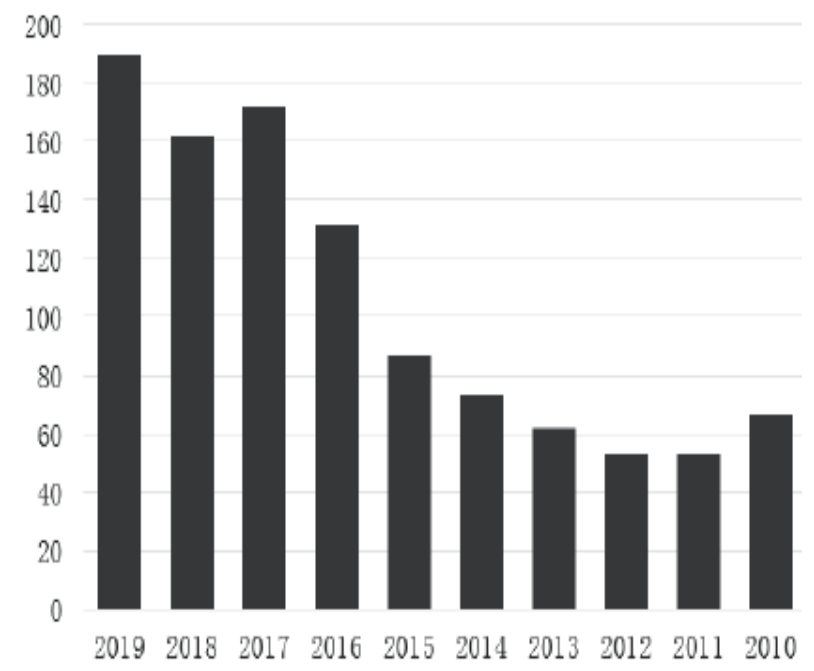

Figure 1. Papers in Web of Science and Google Scholar in the last ten year with key words "AI" and 'Education"[25].

Foreign studies have likewise demonstrated the significance of using virtual education in universities to apply artificial intelligence to education. The advantage of providing and using teaching techniques in different subjects is also explained.

Based on previous studies, which are in agreement with the current study in its general objective: to recognize the importance of the use of applications and its effectiveness in self-learning. Agree on the necessity of adopt artificial intelligence techniques in the educational process in general. While the current study differs from these studies in the scientific method followed, the society, and the literature of previous studies that was utilized in the preparation of the theoretical background of AI. It has used previous studies in the use of it on the professional development of teachers.

\section{Statement of the Problem}

The increasing use of artificial intelligence in various fields shows its great importance. including its role in education, and the improvement of educational institutions.

In the light of what has been presented, we can identify the earnest utilization of AI in domain of education in general and the professional development of teachers, to use this new artificial intelligence method.

\section{Research Questions}

Study questions can be defined as follows:

What is artificial intelligence concept?

How can Artificial Intelligence be applied in the professional development of teachers?

What challenges do AI applications face in the professional development of teachers?

\section{Objectives of the Study}

The current study seeks to achieve the following objectives:

Define the concept of AI and its connection to the times' developments.

Learn about using artificial intelligence in the professional development of teachers.

Identify the challenges facing AI applications.

\section{Importance of the Study}

The importance of the study lies in the next considerations:

To enhance the role of intelligence in teacher's professional development for people interested in the educative process, particularly in the teaching aspect of human resources.

To enrich with this study given the scarcity of research; as per the information on the researcher; in the treatment of the themes of intelligence and its relation with the training and qualification of teachers.

\section{Study Approach}

This study is an analytical approach based on the theoretical study of previous literature. So as to respond to the inquiries of the study, we will identify the concept of artificial intelligence, its importance and its fields, especially in the term of teacher's qualification.

\section{Answer study questions}

Answer to question one: What is the concept of artificial intelligence?

The [6], study seems to think about any algorithms of how to make the computer solve problems. Therefore, artificial intelligence programs and systems are written in any of the programming languages. However, there are some of them dedicated to writing artificial intelligence systems because they have facilities for the programmer, where he often writes data, the data representation process, and the language that perform the search process. The most famous of these languages are Prolog and Lisp.

Le [7], sees that artificial intelligence is part of computer science. It aims at designing intelligent systems that have the same characteristics of intelligence in human behavior. Indeed, it works on the principle of formation matching by which things, events and processes can be described, while using their qualitative properties and their logical and computational relationship. (P. 224).

Answer to the second question: How can artificial intelligence be applied in the professional development of teachers?

This question has been answered through two main axes:

Studies dealing with the application of artificial intelligence in different work environments. 
Studies dealing with electronic professional development for teachers considering the data of the digital age.

First: Studies that dealt with the application of artificial intelligence in different work environments.

The most recent couple of years have seen the ascent of Artificial Intelligence (AI) applications in practically all areas from designing to medicine. The utilization of AI as a device for instructing and learning is increasing across the board ubiquity all finished. The paper of Bhattacharya and Nakhare [26] is an examination in progress to investigate the capability of AI in understudy commitment for professional training in the UAE. Specifically, the attention is on how $\mathrm{AI}$ devices can recreate a one-on-one, tutor/control based, managed learning experience to professional understudies. Besides, the examination plans to gauge the effect of giving such an encounter on understudy execution. The investigation will utilize an exploratory structure to contemplate the viability of an AI-put together tutoring framework with respect to understudy execution. The commitment of this investigation will be to propose a one-on-one intelligent mentoring system with regards to professional examinations, and assess its adequacy of better learning results.

The [8], study came to highlight the most prominent uses of artificial intelligence in the professional development of employees, through:

- Enhanced on-site job training: Technology companies use virtual reality to train employees during business hours. They help to visualize the knowledge that expert analytics supports and provide more accurate diagnostic and correction services. While enhancing employee-specific knowledge education, and some institutions and large companies such as IBM. Also, online collaboration tools that allow employees to exchange experiences and use "work hours" for training or learning from their peers. This increases competitiveness in innovation, includes all branches of the organization, depending on their geographical location. Provide employees with permanently open forums for exchanging ideas, helping them to control their training and development through modern educational content, so that artificial intelligence makes employees want to educate.

- Career path: Cognitive technology can help companies collect and provide information about the career progression of each employee in a customized manner. Individuals can define their career path and align with the specific education experiences necessary to bridge the skills and progress gap. Leading organizations have discovered that probably the most ideal approach to urge learning is to furnish representatives with clearness and devices to act improvement and connection their figuring out how to these ways. Mental activities can make this matter easy by assigning and merging information to employees.

- Very personal training programs: Artificial intelligence may go about as a guide for human resources in understanding and presenting the preferred learning methods for each employee. Human resources (HR) can apply these equivalent standards to make a versatile learning involvement in a comparative appearance and style, and facilitate preparing content from inside and outer sources dependent on components, for example, job history, individual dreams, profession objectives and inclinations, and future vocation.

Thanks to the power of artificial intelligence, employees can receive more specialized recommendations to make sustainable and continuous learning and proactive career management easier. This prompts changeless preparing and advancement of AI arrangements so employees can increase their work performance throughout their careers.

Artificial intelligence is the current most prominent technological revolution and the impact is growing to be enormous in the years to come, on all aspects of our daily lives. The European Union, the USA, China and many other countries are working to put in place strategies to develop and apply AI in all sectors, and strategies on how to teach AI and AI-related skills.

Florea and Radu as computer scientists in universities, explain in their paper artificial intelligence and education [27] the challenges to both prepare the next generations of students for creating the AI applications of tomorrow, and to participate in the development of educational tools that exploit AI advanced algorithms and solutions to the benefit of the learners. This is not an easy task and broad interaction with other scientists, from different fields, is strongly required if we want to successfully succeed in this task.

The study [9] that the professional growth of an employee does not end by the mere acquisition of a job or degree, AI technology plays a role in the continuous training of most employees in the future, in the transfer of skills and experiences from generation to generation where employees move to other companies or retire, can help ensure that they can leave the valuable experience they have gained, as well as take them with them, for example, the engineering giant HONEYWELL has developed augmented reality tools (ar/vr) along with intelligence Artificial, for the experience of work before starting implementation on the ground so that the engineer or employee lives the task required of him, determine the time of completion and cost and identify the potential risks, where employees wear AR headphones during the work of their daily tasks, these points record of everything the engineer does, using the technology of image recognition, which can be turned on, allowing trainees or new aids to experience the role through virtual reality, and the 
information from video images is also used to create tools AR provide feedback in real time while Engineers with their work - alert them to risks or remind them to perform routine tasks when they are in a particular place or when looking at a particular topic.

In an article Lamson [10], leading research and consulting firm GARTNER predicts that AI robots will supply $85 \%$ of customer service interactions by 2020 , and will reach $\$ 33$ trillion in annual economic growth, asking the following question: What AI will apply in representative preparing and advancement? Given the fast pace of innovative and cultural changes, training and development providers need to keep up with the latest methods and methodologies while developing their institutions' learning strategies. Days have gone by with the slogan "One size fits all", where AI will give bits of knowledge dependent on the data measure of information it has gathered and investigated, which will encourage the formation of tweaked instructive projects - quicker than any time in recent memory - and permit admittance to these thoughts and information to build up a superior comprehension of worker practices and foresee needs by suggesting and recognizing content dependent on past conduct. Individual versatile learning is a ground-breaking approach to connect the present workforce, and the test of preparing and improvement is to have the option to get information and increment those plans to expand business esteem.

The purpose behind this paper [25] was to assess the impact of Artificial Intelligence (AI) on training. Starting on an account and structure for evaluating AI identified from a fundamental examination, the extent of the investigation was restricted to the application and impacts of $\mathrm{AI}$ in organization, guidance, and learning.

A subjective examination approach, utilizing the utilization of writing survey as an exploration plan and approach was utilized and viably encouraged the acknowledgment of the investigation reason. Artificial knowledge is an eld of study and the subsequent advancements and improvements that have finished in PCs, machines, and different antiques having human-like insight portrayed by psychological capacities, learning, flexibility, and dynamic abilities. The investigation discovered that AI has broadly been received and utilized in instruction, especially by training establishments, in various structures.

Man-made intelligence at first appeared as PC and PC related innovations, changing to electronic and online wise training frameworks, and at last with the utilization of installed PC frameworks, along with different advances, the utilization of humanoid robots and electronic chatbots to play out educators' obligations and capacities autonomously or with teachers.

Utilizing these stages, educators have had the option to perform diverse regulatory capacities, for example, inspecting and reviewing understudies' tasks all the more adequately and efficiently, and accomplish higher caliber in their instructing exercises. Then again, on the grounds that the frameworks influence AI and versatility, educational plan and substance have been tweaked and customized in accordance with understudies' needs, which has encouraged take-up and maintenance, subsequently improving students experience and by and large nature of learning.

The study showed that artificial intelligence aided education includes intelligent education, innovative virtual learning, and data analysis and prediction. Major scenarios of AI in education and key technologies supporting are listed in (Table 1). Note that AI-enable education is playing a more important role as learning requirements promotes.

Table 1. Techniques for scenarios of AI education.

\begin{tabular}{|c|c|}
\hline Scenarios of Al education & AI - related techniques \\
\hline $\begin{array}{c}\text { Assessment of students and } \\
\text { schools }\end{array}$ & $\begin{array}{c}\text { Adaptive learning method and } \\
\text { personalized learning approach, } \\
\text { academic analytics }\end{array}$ \\
\hline $\begin{array}{c}\text { Grading and evaluation of } \\
\text { paper and exams }\end{array}$ & $\begin{array}{c}\text { Image recognition, computer - } \\
\text { vision, prediction system }\end{array}$ \\
\hline $\begin{array}{c}\text { Personalized intelligent } \\
\text { teaching }\end{array}$ & $\begin{array}{c}\text { Data mining or Bayesin knowledge } \\
\text { interference, intelligent teaching } \\
\text { systems, learning analytics }\end{array}$ \\
\hline $\begin{array}{c}\text { Smart School } \\
\text { Face recognition, speech } \\
\text { recognition, virtual labs, AR, VR, } \\
\text { hearing and sensing technologies }\end{array}$ \\
\hline $\begin{array}{c}\text { Edge computing, virtual } \\
\text { personalized assistants, real-time } \\
\text { andinglys }\end{array}$ \\
\hline
\end{tabular}

Second: Studies that dealt with the electronic professional development of teachers in the light of the data of the digital age.

Studies on the professional development of teachers through the digital age are entry point for artificial intelligence, [11] a study, where computers have been used in education for more than thirty years. Computer based training and based learning AIDED INSTRUCTION are the first systems in existence computer-based teaching attempts. These systems were not designed to respond the learner' individual needs, but rather decisions regarding the mobility and movement of the student. Also, the scientific material was controlled in a scheme, and was not done in advance as indicated by the learner's abilities.

Although CBT and CAI systems are effective in helping learners, they do not provide individual care to the student as the natural (human) teacher does. In order for the computerized education system to provide such care, the system must think about both the specialized domain and the learner himself. This has encouraged research in building intelligent learning systems and providing smarter materials with a greater capacity to meet the needs of the student. It acquires the property of intelligence through its ability to present educational decisions on the course of the learning cycle just as to secure data on the personality of the learner, thus providing great diversity by modifying the interactions between system and student. 
Field studies have demonstrated that smart learning systems are highly effective. He explained [12], that the start use of AI methods in education is due to the Program Scholar to teach the geography of South America. Besides, the use of a geographical knowledge base that was not just pre-recorded texts. One of the novel thoughts in this program was that it is possible for both the program or the student to take the initiative in the dialogue.

The world is currently witnessing a fast increment in the utilization of innovation in instruction. Classrooms in the Middle East are expected to move closer from the traditional framework of learning to smart education, in which artificial intelligence is central, where a mix of robots and customized artificial intelligence and teachers will be used. According to experts, the large and growing proportion of young individuals in the district will profit by robots that are patient and flexible, also classroom teachers will be freed from administrative matters and will be free to focus on students.

Smart learning systems are defined as computer-based learning systems with independent databases. Knowledge bases are for educational content (which determine what is taught) as well as teaching strategies (which define how to teach). It tries to use conclusions about the learner's ability to understand subjects and distinguish their qualities and defects. With the goal that they can dynamically adapt the learning process, the intelligent learning system consists of:

- Knowledge of the educational field (the specialized curriculum to be introduced or learned).

- Know about the learner.

- Knowledge of education strategies.

- CAI-based learning systems differ from their smart systems.

- The difference between traditional and intelligent systems lies in two basic assumptions.

- Individual education (directed to one person) by an efficient teacher, who is more detailed than education through the classroom style; on the grounds that both the substance and the strategy for training can be constantly adapted to fulfill the needs of the situation (the educational situation of the individual).

Students learn better in environments close to where they use their knowledge, which means "learning by practice". They learn from their faults and by shaping and elaborating their knowledge in a very particular individual way. These two assumptions determine the rationale for intelligent learning systems.

The [13], noted the importance of electronic professional development as a modern trend in the training of teachers in service. Professional development is an essential and integral aspect of a teacher's profession. With the Internet's explosion in the developing and developed countries, teachers are beginning to experiment, individually and informally, with self-managed and self-directed online professional development. Not many have sensed its importance to teachers' enhancement of professional development, analyzed the implications, and put forward some suggestions which facilitate and lead to effective online professional development, and several studies have emerged that emphasized the value of electronic professional development for teachers, such as study [14],[15],[16].

These studies have joined with the effectiveness of e-training programmers in the professional development of teachers in general. Also, they have shown the viability (e-course management systems) in managing professional development programmers and their significant advantages in this area. The use of e-learning in the professional development of teachers contributes significantly to the efficiency of online professional development programmers because of their different advantages. It has demonstrated the requirements of e-professional development and considered good planning in the light of teachers' perceptions and needs as one of the most important effectiveness of e-professional development.

The digital revolution has contributed to the emergence of many modern educational trends in the field of teacher preparation and training in the service. This is the consequence of the interaction of teacher preparation and training institutions with contemporary variables. Because of the explosion the blast of information and the improvement of communication technologies and the entry into information technology, or the so-called digital age, and the subsequent changes in learning environments, it has gotten important to focus on the professional development of teachers to keep up with these changes and to know how to cope with them, which reflects on the preparation of students to understand this digital age, to engage in it and to acquire the necessary skills to deal with it[17].

It has become necessary to employ teaching and learning techniques in the professional development of teachers to train them, and to raise their performance and productivity. This has required attention to the professional development of teachers in order to meet the demands of education in the digital age. It is not acceptable that the professional development of the teacher remains immune to the effects of the digital age. Especially since its content and the way it is presented, and even when, where and how it is presented to the teacher, are available to the teacher at all the time and everywhere.

In the framework of the digital competence of European teachers "Dig Comp Edu", it is mentioned that teachers need wider and more complex skills than ever before. Advanced gadgets are everywhere and are obliged to help students develop their knowledge. They expect teachers to develop their computer skills. At the international and public level, various structures, self-assessment tools and preparation plans have been created to describe the characteristics of teachers' advanced capabilities and help them assess their talents, distinguish their preparation needs and make offers. Prepare to be the teacher. Break down and group these tools [28]. As show in the (Figure 2). 


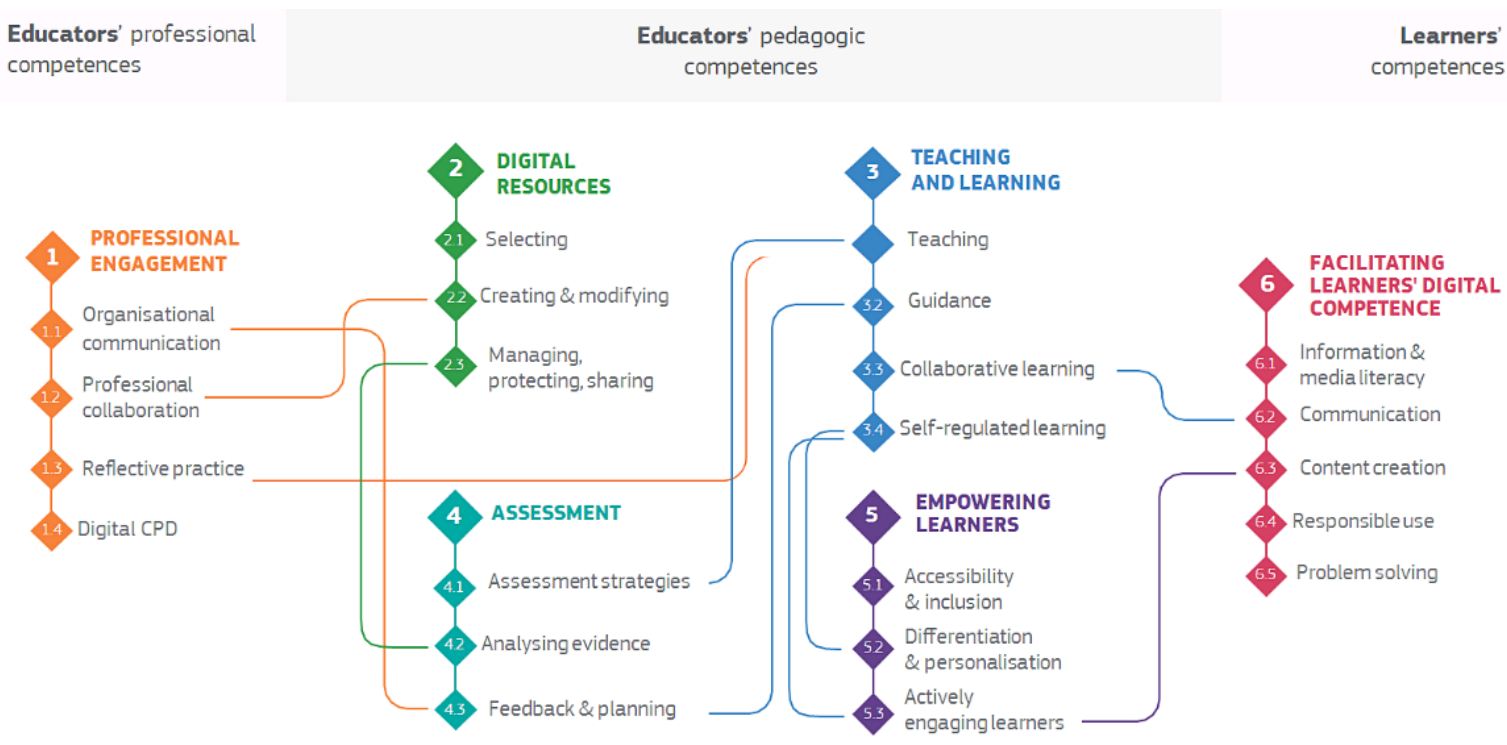

Figure 2. Dig Comp Edu competences and their connections [28]

The six Dig Comp Edu areas focus on different aspects of educators' professional activities:

Area 1: Professional Engagement Using digital technologies for communication, collaboration and professional development.

Area 2: Digital Resources Sourcing, creating and sharing digital resources.

Area 3: Teaching and Learning Managing and organizing the utilization of computerized advances in educating and learning.

Area 4: Assessment Using advanced innovations and systems to improve evaluation.

Area 5: Empowering Learners Using advanced innovations to upgrade consideration, personalization and students' dynamic commitment.

Area 6: Facilitating Learners' Digital Competence Enabling students to innovatively and dependably utilize computerized advances for data, correspondence, content creation, prosperity and critical thinking.

The study [18], showed the most important justifications for the interest in the electronic professional development of teachers as follows:

- Technological development and its implications for the educational process, in terms of employment, learning techniques and education.

- Information technology and computers have radically affected education systems and methods.

Requiring students to be helped acquire self-learning, collaborative learning and distance learning skills, as well as increased attention to the professional development of faculty members in order to improve the effectiveness of educational outcomes [19].

The digital age is characterized by the explosion of knowledge and technology, the proliferation of communications systems, the increasing use of computers and the expansion of the use of the Internet. The states are beginning to feel the growing importance of information education and technological culture. By providing an interactive learning and training environment. By attracting the attention of individuals in an era characterized by rapid development and constant change.

The use of information technology and the Internet in training and education is one of the most important indicators of society's transformation into an information society. As this will contribute to increasing the efficiency and effectiveness of education systems and in spreading information awareness. Thus, it will be contributing to the building of the information cadres that societies seek in the digital age.

The change in teacher roles: the development of communication techniques and the multiplicity of learning sources have led to fundamental changes, in the requirements of the educational situation; in terms of the means of knowledge transfer and the roles of the teacher. Which have shifted from traditional roles that consider the teacher to be merely a communicator to facilitator, facilitator, guide and mentor to his students.

The quantity of qualified educators in different controls is inadequate comparable to the high extent of recently prepared instructors, and the gathering comes up short on the aptitudes and experience to assume its job adequately.

Here, we contend that one of the possible parts of AI in instruction is to give chances to expand human insight, with AI supporting us in dynamic cycles, as opposed to supplanting us with mechanization.

So as to give observational proof to help our contention, we present a contextual investigation with regards to discuss coaching, in which we use forecast and order models to build the straightforwardness of the natural choice cycles of master mentors for cutting edge reflection and input. 


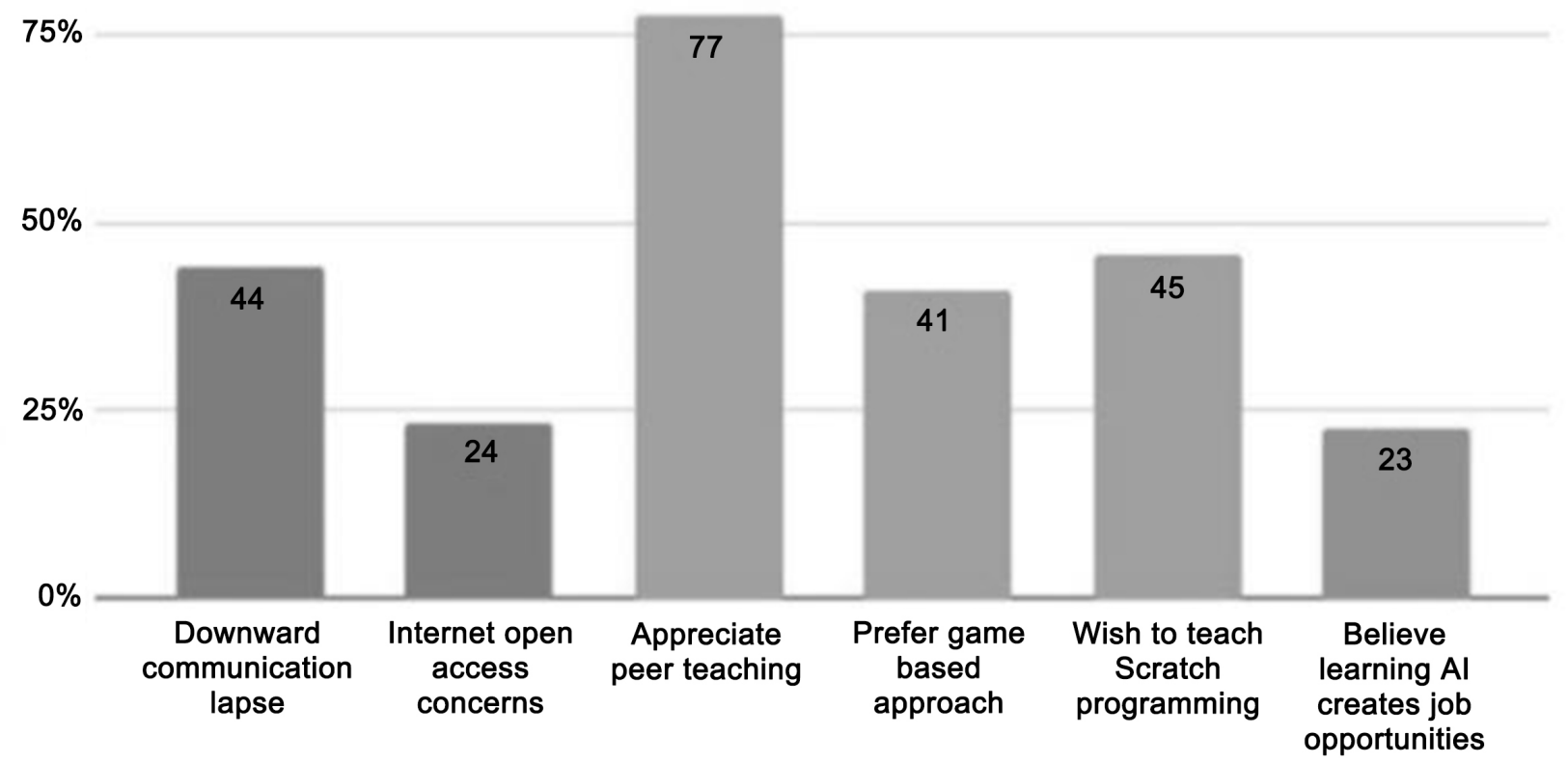

Teachers' Perceptions Recorded from Al Teacher Education Program

Figure 3. Observation on teachers perceived challenges, perspectives and belief states [29]

Moreover, the exactness of unimodal and multimodal order models of master human coaches' choices with respect to the social and enthusiastic parts of mentoring while assessing learners was thought about. Our outcomes show that multimodal information prompts more exact arrangement models in the setting we considered, the ever-expanding number of understudies selected training.

The subsequent increase in demand for teachers with different qualifications and specialties. Challenging quality in education, achieving quality in education, demanding accreditation and achieving competitive advantage, has become a challenge for education officials. It needs more advanced training for teachers in order to increase their efficiency and productivity, which calls for the use of modern technology to achieve more professional development for teachers [20].

The increasing pervasiveness of artificial intelligence in consumer products, toys and various smart technologies and applications creates the need for today's generation of children to better understand this technology. One way to achieve this kind of understanding and resourcefulness is to engage meaningfully in $\mathrm{AI}$ in an educational context. The integration of AI literacy and reflection into school curricula is in its infancy in various countries.

The article by Vazhayil et al [29] focuses on training teachers to introduce $\mathrm{AI}$ in schools by exploring the efforts highlighted in the implementation of the AI program in schools through teacher training programs in India. The perspectives of teachers at the beginning and end of training were observed, and the challenges reported by teachers regarding influencing factors such as gaps in political communication, infrastructure, pedagogy, content provision, and cultural influence in the context of Indian schools were examined. Results in (figure 3) indicate, among other things, a low belief among teachers in the potential of $\mathrm{AI}$ and interest in exploring peer teaching and play-based approaches to introducing AI in the classroom.

One of the most important effects of the digital age on the professional development of teachers has been the emergence of a new system of teacher training and the improvement of their professional skills. The e-learning system, which depends on communication and information technologies in the activities necessary for the professional development process to include e-learning, e-training, which is not only to send scientific material to the beneficiaries, but also to include all the steps and procedures of management, training and monitoring of the training process. In fact, there are many justifications for the introduction of e-learning in the field of teacher professional development, including the problems of traditional training, such as:

- The lack of strategic planning of teacher training systems and programmers: training topics are not chosen in the light of a comprehensive study of teachers' needs in general

- The lack of continuity of training programs necessary for professional development, with the intervals of training programs attended by teachers that may be up to several years

- The lack of training programs for teachers and their distance from keeping pace with the change in the objectives, methods and modern methods of professional development of teachers. 
- The lack of the previous programs to follow modern concepts of professional development, and the applications that should accompany them [21].

- Traditional methods of training teachers by relying on specific methods such as lectures, teaching

- Lack of interest in discussion workshops, workshops, and therefore little interest in acquiring skills and concentrating on theoretical information.

- Typical methods and assessment methods in traditional teacher education programs and focus on certain means such as attendance and attendance or editorial tests that depend on preservation.

Answer to the third question: What are the challenges facing AI applications in the professional development of teachers?

This work paper [22], points to several challenges facing the application of artificial intelligence in general in the educational and educational field, most notably:

- $\quad$ Lack of specialized staff.

- Lack of infrastructure of wireless communications, computers, and software.

- Rehabilitation of teacher trainers and develop their traditional skills to suit the technique of learning and computer use.

- Give more advantage to professionals of these techniques over other students.

- Increased isolation due to increased indirect communication, not everyone is required to be in one place such as traditional education.

He [23], stated that there are a number of challenges facing the application of artificial intelligence in the social field, the most important of which are:

- The need to change the culture of society.

- Raising awareness of the wrong uses of technology and its impact on society.

- Teachers and students need continuous training in these devices and techniques.

- Designing and preparing appropriate curricula.

- Private learning management systems are still in their early stages.

In 2020, there were few recent studies on Artificial Intelligence (AI) in education. With the progressive integration of information technology and education and teaching, these studies show that the innovative application of computerization in education has brought new opportunities for the evaluation and professional development of teachers.

These articles integrate recognition in action and reflection in practice with AI technology, and establish a new framework for the evaluation of teacher development based on pedagogical reflection which strengthens our study in terms of the exploitation of AI in education and develops the role of the teacher vis à vis e-learning. They integrate process diagnosis and reflective practice supported by intelligent technology for the evaluation of past teaching, in order to provide a theoretical and practical reference for the implementation of teacher development assessment in the context of wisdom education.

\section{Conclusions}

In light of the above, artificial intelligence has begun to occupy a significant spot in numerous territories, including education. Especially towards raising teachers' competence to use artificial intelligence. Hence the requirement to bring more artificial intelligence to the education.

Previous studies have proven the adequacy of human improvement programs. In two decades at the latest, AI systems were occupying most of human life. It is then inevitable to manage them dependent on the measure of information put away and the way they are processed. In addition, the responsible for teacher professional development programs should take seriously the question of the benefits from artificial intelligence in teacher education, relying on it as human intelligence.

Based on the results of the study, the following recommendations were made:

- Designing educational software based on artificial intelligence to raise the qualifications of teachers.

- Building training pathways based on artificial intelligence for all those working in education field.

- Provide accurate databases in all areas of education, including human resources.

- $\quad$ Providing educational training environments that add to improving the part of AI applications in the professional development of teachers.

- Training of HR trainers on using artificial intelligence in the training of teachers, previously and during service.

- $\quad$ Linking databases within a global network that helps challenge teachers' career paths.

- Using increased and computer-generated reality in training teachers and preparing them educationally and academically for the educational process.

- We made some proposals to activate those recommendations, including:

- Conducting semi-experimental studies based on the effectiveness of the use of artificial intelligence in the professional development of teachers.

- Conducting studies measuring the impact and returning on training for AI applications in the training and qualification of teachers.

- Conducting pilot studies on the AI applications (virtual reality, augmented reality) in internship and qualifying teachers before and during service.

\section{REFERENCES}

[1] Al-Hadi, Muhammad (2005). E-learning via the Internet, 
Cairo, the Egyptian Lebanese House.

[2] Al-Sharia, A. \& Abdullah, S. (2000). Computer and its systems, Amman: Wael Publishing House.

[3] Qandil, Hind (2016). The use of neural networks - artificial intelligence - in predicting future economic growth in Egypt, Journal of Future Studies - Sudan University of Science and Technology, 17 (2) 1-2.

[4] Al-Sharqawi, M. (2011), Artificial Intelligence and Neural Networks, Baghdad: Emirates of Imam Jaafar Al-Sadiq University.

[5] Al-Ritimi, Muhammad (2012), Artificial Intelligence in Education: Smart Learning Systems, Date of Entry 23/7/2019 http://www.arteimi.info/site/home.html

[6] Al-Hussaini, Osama (2002), the language of logo, Riyadh, Ibn Sina Library, first edition.

[7] Othman, Hussein Atman Jamil, Ahmed Adel (2012). The possibility of using artificial intelligence techniques to control the quality of internal audit, the eleventh annual scientific conference, April 23-26, 2012, Al-Zaytoonah University.

[8] Varghese, E. (2018) Artificial Intelligence is Revolutionizing Employee Development, Online available from:

https://www.ibm.com/smarter-workforce/ai-revolutionizin g-employee-development

[9] Marr, B. (2019) Artificial Intelligence in The Workplace: How AI Is Transforming Your Employee Experience, Online available from: https:/www.forbes.com/sites/berna rdmarr/artificial-intelligence-in-the-workplace-how-ai-is-tr ansforming-your-employee-experience/\#65fd04d453ce

[10] Al-Ritimi, Muhammad (2012), Artificial Intelligence in Education: Smart Learning Systems, Date of Entry 23/7/2019 http://www.arteimi.info/site/home.html

[11] Yunus, M. (2018): How to achieve the electronic professional development of teachers in light of Digital era data, 5/27/2016. Retrieved on com.ed-new

[12] Schaverien, L. (2001). Teacher Education in Generating Virtual Classroom: A Web-Delivered Context for Developing Learning Theories, Paper presented at the Annual Meeting of the American Educational Research Association (Seattle, WA, April 10-14, 2001).

[13] Kabilan, Muhammad Kamarul, (2003), online professional development of teachers: an examination of structure and trends in Malaysia, International Journal of Instructional Media;2003, Vol. 30 Issue 4, p367

[14] Wei, F. (2007). A student model for an intelligent tutoring system helping novices learn object -oriented design, doctoral dissertation, Lehigh University, Pennsylvania, USA.

[15] Hadjerrout, S. (2010), Developing Web-Based Learning Resources in School Education: A User-Centered Approach Interdisciplinary, Journal of E-Learning and Learning Objects. Volume 6, 2010 • pp. 115-135.

[16] Wei, F. (2007). A student model for an intelligent tutoring system helping novices learn object -oriented design, doctoral dissertation, Lehigh University, Pennsylvania, USA.
[17] Woods, G. (2004). Student perceptions of web -based technologies, principles of good practice, and multiple intelligences, doctoral dissertation, lliant International University, San Diego, USA.

[18] Shehata,H and Al-Najjar, Zeinab, (2003) Lexicon of Educational and Psychological Terms Cairo: The Egyptian Lebanese House

[19] Cukurova, Mutlu, Kent, Carmel, and Luckin, Rosemary,(2019), Artificial intelligence and multimodal data in the service of human decision - making: A case study in debate tutoring, British journal of educational technology. Volume 50,2019 - Issue6.

[20] Björk, Greta and Hatlevik, Ove, (2017), Newly qualified teachers' professional digital competence: implications for teacher education, European Journal of Teacher Education, Volume 41, 2018 - Issue 2

[21] Amanda, Andrea, M.\&Mike (2006) eLearning Evaluation, In E-learning Concepts and Techniques, Institute for Interactive - Technologies, Bloomsburg University of Pennsylvania, USA.

[22] UNESCO, (2019) Artificial Intelligence in Education: Challenges, Published in 2019 by the United Nations, Educational, Scientific and Cultural Organization, DMS: 29219 ED-2019/WS/8 and Opportunities for Sustainable Development

[23] Perc, Matjaž, Ozer, Mahmut \& Hojnik, Janja (2019) Social and juristic challenges of artificial intelligence, Humanities and Social Sciences Communications, Palgrave Commun 5 , 61 (2019)

[24] Liu Yangjun, Li Hao \& Chen Rong M (2020), Research on Artificial Intelligence Assisted Teacher Developmental Evaluation from the Perspective of Reflective Practice, International Conference on Big Data and Informatization Education (ICBDIE), 23-25 April 2020, Zhangjiajie, China, China.

[25] L. Chen, P. Chen, and Z. Lin, "Artificial Intelligence in Education: A Review," IEEE Access, vol. 8, pp. 75264 $75278,2020$.

[26] P. Bhattacharya and S. Nakhare, "Exploring AI-enabled Intelligent Tutoring System in the Vocational Studies Sector in UAE," ITT 2019 - Inf. Technol. Trends Emerg. Technol. Blockchain IoT, pp. 230-233, 2019

[27] adina Magda Florea and Nerban Radu (2019) artificial Intelligence and Education, 2019 22nd International Conference on Control Systems and Computer Science (CSCS), 28-30 May 2019, Bucharest, Romania, Romania

[28] T. Kohler, H. W. Wollersheim, and C. Igel, "Scenarios of Technology Enhanced Learning (TEL) and Technology Enhanced Teaching (TET) in Academic Education A Forecast for the Next Decade and its Consequences for Teaching Staff.," Proc. - 2019 8th Int. Congr. Adv. Appl. Informatics, IIAI-AAI 2019, vol. 7, pp. 240-245, 2019.

[29] A. Vazhayil, R. Shetty, R. R. Bhavani, and N. Akshay, "Focusing on Teacher Education to Introduce AI in Schools: Perspectives and Illustrative Findings," Proc. - IEEE 10th Int. Conf. Technol. Educ. T4E 2019, pp. 71-77, 2019. 